\title{
Article \\ Detection of Sub-Micro- and Nanoplastic Particles on Gold Nanoparticle-Based Substrates through Surface-Enhanced Raman Scattering (SERS) Spectroscopy
}

\author{
Jessica Caldwell ${ }^{1}\left(\mathbb{D}\right.$, Patricia Taladriz-Blanco ${ }^{1, *}$, Barbara Rothen-Rutishauser ${ }^{1}\left(\mathbb{D}\right.$ and Alke Petri-Fink ${ }^{1,2, *(\mathbb{D})}$ \\ 1 Adolphe Merkle Institute, University of Fribourg, Chemin des Verdiers 4, 1700 Fribourg, Switzerland; \\ jessica.caldwell@unifr.ch (J.C.); barbara.rothen@unifr.ch (B.R.-R.) \\ 2 Department of Chemistry, University of Fribourg, Chemin du Musée 9, 1700 Fribourg, Switzerland \\ * Correspondence: patricia.taladrizblanco@unifr.ch (P.T.-B.); alke.fink@unifr.ch (A.P.-F.)
}

Citation: Caldwell, J.;

Taladriz-Blanco, P.;

Rothen-Rutishauser, B.; Petri-Fink, A.

Detection of Sub-Micro- and

Nanoplastic Particles on Gold

Nanoparticle-Based Substrates

through Surface-Enhanced Raman

Scattering (SERS) Spectroscopy.

Nanomaterials 2021, 11, 1149. https://

doi.org/10.3390/nano11051149

Academic Editor: Maurizio

Muniz-Miranda

Received: 30 March 2021

Accepted: 23 April 2021

Published: 28 April 2021

Publisher's Note: MDPI stays neutral with regard to jurisdictional claims in published maps and institutional affiliations.

Copyright: (C) 2021 by the authors. Licensee MDPI, Basel, Switzerland. This article is an open access article distributed under the terms and conditions of the Creative Commons Attribution (CC BY) license (https:/ / creativecommons.org/licenses/by/ $4.0 /)$.

\begin{abstract}
Small plastic particles such as micro- $(<5 \mathrm{~mm})$, sub-micro- $(1 \mu \mathrm{m}-100 \mathrm{~nm})$ and nanoplastics $(<100 \mathrm{~nm})$ are known to be ubiquitous within our surrounding environment. However, to date relatively few methods exist for the reliable detection of nanoplastic particles in relevant sample matrices such as foods or environmental samples. This lack of relevant data is likely a result of key limitations (e.g., resolution and/or scattering efficiency) for common analytical techniques such as Fourier transform infrared or Raman spectroscopy. This study aims to address this knowledge gap in the field through the creation of surface-enhanced Raman scattering spectroscopy substrates utilizing spherical gold nanoparticles with $14 \mathrm{~nm}$ and $46 \mathrm{~nm}$ diameters to improve the scattering signal obtained during Raman spectroscopy measurements. The substrates are then used to analyze polystyrene particles with sizes of $161 \mathrm{~nm}$ or $33 \mathrm{~nm}$ and poly(ethylene terephthalate) particles with an average size of $62 \mathrm{~nm}$. Through this technique, plastic particles could be detected at concentrations as low as $10 \mu \mathrm{g} / \mathrm{mL}$, and analytical enhancement factors of up to 446 were achieved.
\end{abstract}

Keywords: nanoplastic; sub-microplastic; Raman; SERS; nanoparticles

\section{Introduction}

As a result of the degradation of products composed of synthetic polymers such as polystyrene (PS), poly(ethylene terephthalate) (PET), polypropylene (PP), and polyethylene (PE) (e.g., food and beverage packaging), small particles, commonly referred to as micro$(<5 \mathrm{~mm})$, sub-micro- $(1 \mu \mathrm{m}-100 \mathrm{~nm})$ and nanoplastics $(<100 \mathrm{~nm})$, are highly prevalent within our surrounding environment. Studies have reported the presence of microplastic particles within various products meant for human consumption [1,2] (e.g., due to the previous ingestion of plastics by fish and shellfish meant for consumption) as well as in samples collected from oceans [3], soils [4], and the atmosphere [5] worldwide. However, as a result of their exceptionally small size and low estimated concentrations within such environments [6], studies which report the presence of sub-micro- and nanoplastic particles are limited [7].

Among the techniques most commonly utilized within studies which quantify plastic particle presence in food and environmental samples, Raman spectroscopy is one of the most promising for the detection of sub-micro- and nanoplastic particles due to its reported viability for smaller plastic particles (i.e., microplastics $\sim 1 \mu \mathrm{m}$ or larger in size [8]) compared to other techniques such as stereomicroscopy (i.e., microplastics $\sim 500 \mu \mathrm{m}$ or larger in size [9]) or Fourier transform infrared spectroscopy (FTIR) (i.e., microplastics $\sim 10 \mu \mathrm{m}$ or larger in size [8]). However, due to the diffraction limited instrument resolution for optical microscopy setups (i.e., half the wavelength of the excitation light utilized) and the low probability of spontaneous Raman scattering (i.e., 1 in $10^{8}$ of the incident radiation undergoes Raman scattering), conventional Raman spectroscopy is not sensi- 
tive enough to address the issue of sub-micro- and nanoplastic particle detection without further modifications [10-12].

One such modification used to overcome the current analytical limitations of Raman spectroscopy is the technique knowns as surface-enhanced Raman scattering (SERS) spectroscopy, which involves placing the sample of interest in close proximity to or adsorbing it to a plasmonic metal surface; predominantly gold $(\mathrm{Au})$ and silver $(\mathrm{Ag})$ [13-15]. This technique takes advantage of the plasmonic oscillations of the surface electrons surrounding the metal surface to enhance the inelastic Raman scattering signal of the analyte, with enhancement factors of up to $10^{14}-10^{15}$ reported for optimized systems [13].

Despite such promising signal improvements being reported for other systems, to date relatively little literature exists which discusses the use of the SERS for the detection of submicro- or nanoplastic particles. $\mathrm{Xu}$ et al. have reported the use of a commercially available Klarite substrate to detect particles composed of PET, PS, and poly(methyl methacrylate) (PMMA) with signal enhancements of up to 2 orders of magnitude [16]. However, the particles analyzed in this study were all reported to be $>360 \mathrm{~nm}$ in size [16]; thus exceeding the maximum size (i.e., $100 \mathrm{~nm}$ ) defined for a nanomaterial by the European Commission [17]. In a study conducted by Lv et al. it was reported that the detection of PS particles with a diameter of $100 \mathrm{~nm}$ was possible, and that the enhancement factors observed could be as much as 500 times greater than a regular Raman spectroscopy signal [18]. This enhancement was achieved through the aggregation of silver nanoparticles (AgNPs) with salts [18]. Thus, there is still a great need in the field for cheap, reproducible SERS substrates that can be used to detect sub-micro- or nanoplastic particles; particularly when the sample of interest contains a very low concentration of plastics (e.g., more environmentally relevant concentrations on the order of nanograms) [6].

This study aims to address this gap in the field through using SERS substrates fabricated through the layer-by-layer technique. The high potential of SERS as an analytical technique is strictly linked to the development of highly reproducible and reliable substrates. Therefore, when using colloidal nanoparticles as SERS substrates, control over their synthesis is required [19]. However, the preparation of highly reproducible monodisperse AgNPs is much more difficult than for gold nanoparticles (AuNPs) due to the higher reactivity of Ag atoms than Au atoms [20]. In addition, it has been reported in the literature that AgNPs undergo dissolution in aqueous solutions, which limits their applicability as SERS substrates, especially for environmental samples [21]. Based on this, despite the larger scattering contribution and thus higher SERS enhancement factor of AgNPs compared to AuNPs, this study was conducted utilizing $14 \mathrm{~nm}$ and $46 \mathrm{~nm}$ spherical AuNPs. As a proof of concept, PS particles with sizes of 161 or $33 \mathrm{~nm}$ and PET particles with a size of $62 \mathrm{~nm}$ were detected with concentrations as low as $10 \mu \mathrm{g} / \mathrm{mL}$.

\section{Materials and Methods}

\subsection{Materials}

Tetrachloroauric acid $\left(\mathrm{HAuCl}_{4} \cdot 3 \mathrm{H}_{2} \mathrm{O}, \geq 99.9 \%\right)$, sodium citrate tribasic dihydrate $\left(\mathrm{C}_{6} \mathrm{H}_{5} \mathrm{Na}_{3} \mathrm{O}_{7} \cdot 2 \mathrm{H}_{2} \mathrm{O}, \geq 99.5 \%\right)$, sodium dodecyl sulfate (SDS; ACS reagent; $\mathrm{NaC}_{12} \mathrm{H}_{25} \mathrm{SO}_{4}$; $\geq 99.9 \%)$, poly(allylamine hydrochloride) $\left(\mathrm{PAH} ;\left[\mathrm{CH}_{2} \mathrm{CH}\left(\mathrm{CH}_{2} \mathrm{NH}_{2} \cdot \mathrm{HCl}\right)\right]_{n}\right.$; average $\mathrm{Mw}$ 17,500), and styrene (ReagentPlus ${ }^{\circledR}$ reagent; $\mathrm{C}_{8} \mathrm{H}_{8} ; \geq 99.9 \%$ ) were purchased from SigmaAldrich, Buchs, Switzerland. Hydroxylamine hydrochloride $\left(\mathrm{NH}_{2} \mathrm{OH} \cdot \mathrm{HCl}, \geq 99.0 \%\right)$ and potassium peroxodisulfate (KPS; ACS reagent; $\mathrm{K}_{2} \mathrm{~S}_{2} \mathrm{O}_{8}, \geq 99.9 \%$ ) were purchased from Fluka, Buchs, Switzerland. Hydrogen peroxide $\left(\mathrm{H}_{2} \mathrm{O}_{2}, 30\right.$ wt. $\%$ in $\left.\mathrm{H}_{2} \mathrm{O}\right)$ was purchased from Reactolab SA, Servion, Switzerland. Sulfuric acid (ISO + Ph. Eur. Reagent; $\mathrm{H}_{2} \mathrm{SO}_{4}$, $\geq 95 \%)$ was obtained from Honeywell, Regen, Germany. PET $\left(\left[\mathrm{C}_{10} \mathrm{H}_{8} \mathrm{O}_{4}\right]_{n}\right)$ pellets were purchased from Goodfellow Cambridge Ltd., Huntingdon, UK. All water was purified with an 18.2 M $\Omega . c m$ arium 611DI MilliQ system (Sartorius Stedim Biotech, Göttingen, Germany) prior to use. 


\subsection{Preparation of Gold and Plastics Particles}

Sub-micron PS particles with a $161 \mathrm{~nm}$ diameter were prepared by adding $16.1 \mathrm{~g}$ of styrene to an SDS solution (149 $\mathrm{mg}$ SDS dissolved in $59 \mathrm{~mL}$ of MilliQ water under $300 \mathrm{rpm}$ stirring) previously degassed with $\mathrm{N}_{2}$. The final emulsion was degassed with $\mathrm{N}_{2}$ and heated to $60^{\circ} \mathrm{C}$ for $1 \mathrm{~h}$. The temperature was then increased to $80^{\circ} \mathrm{C}$ for $45 \mathrm{~min}$ before $3.33 \mathrm{~mL}$ of a KPS stock solution (195 mg in $20 \mathrm{~mL}$ of MilliQ water) was introduced dropwise over the course of $10 \mathrm{~min}$. The reaction was stirred at $80^{\circ} \mathrm{C}$ overnight. To purify, particles were dialyzed using a $14 \mathrm{kDa}$ cutoff membrane (Carl Roth $\mathrm{GmbH}+\mathrm{Co}$, Arlesheim, Switzerland) for 3 weeks.

PS particles with a $33 \mathrm{~nm}$ diameter were synthesized by mixing $2 \mathrm{~g}$ of styrene with $480 \mathrm{mg}$ SDS and $11 \mathrm{~mL}$ of MilliQ water under $300 \mathrm{rpm}$ stirring. The final emulsion was degassed with $\mathrm{N}_{2}$ and heated to $75^{\circ} \mathrm{C}$ for 30 min prior to the dropwise addition of $1 \mathrm{~mL}$ of a KPS solution (16.6 mg in $1 \mathrm{~mL}$ of MilliQ). The reaction was then stirred at $75{ }^{\circ} \mathrm{C}$ under $\mathrm{N}_{2}$ flux for $5 \mathrm{~h}$. To purify, particles were dialyzed using a $14 \mathrm{kDa}$ cutoff membrane (Carl Roth $\mathrm{GmbH}+\mathrm{Co}$, Arlesheim, Switzerland) for 1 week.

For both types of PS particles, stock concentrations were acquired by mass balancing the dried particle powders obtained from a fixed $(1 \mathrm{~mL})$ volume using an AG204 Delta Range balance (Mettler-Toledo $\mathrm{GmbH}$, Greifensee, Switzerland). This process was repeated 6 times to obtain the final, average stock concentration.

PET particles with an average diameter of $62 \mathrm{~nm}$ were prepared using the sequential milling method previously described by Caldwell et al. [22]. Briefly, PET pellets were milled under liquid-nitrogen cooling with a 6770 Freezer Mill (steel milling rod; steel chamber plugs; polycarbonate chamber; SPEX, Metuchen, NJ, USA) prior to milling at $15{ }^{\circ} \mathrm{C}$ in a NanoWitt-Lab mill (zirconium dioxide beads; FREWITT SA, Granges-Paccot, Fribourg, Switzerland). To purify, milled particle dispersions were run through a Chromafil filter with a pore size of $0.2 \mu \mathrm{m}$ (Macherey-Nagel, Düren, Germany) and dialyzed in a membrane with a $14 \mathrm{kDa}$ cutoff. Complete production and characterization details for the milled PET particles have been reported previously [22].

AuNPs with a $14 \mathrm{~nm}$ diameter were prepared via the Turkevich method [23]. Briefly, an aqueous solution of $\mathrm{HAuCl}_{4}(0.5 \mathrm{mM})$ was brought to reflux and mixed with $1.7 \mathrm{mM}$ sodium citrate for $15 \mathrm{~min}$. The solution was then allowed to cool to room temperature while stirring prior to UV-vis characterization. The dispersion was kept in the fridge until further use.

AuNPs with a $46 \mathrm{~nm}$ diameter were prepared via the Brown method with slight modifications [24]. Briefly, $0.0125 \mathrm{mM}$ of as-prepared $14 \mathrm{~nm}$ AuNPs were added to an aqueous solution of $\mathrm{HAuCl}_{4}(0.25 \mathrm{mM})$ and of sodium citrate $(0.5 \mathrm{mM})$ under magnetic stirring. A solution of $\mathrm{NH}_{2} \mathrm{OH} \cdot \mathrm{HCl}(1.96 \mathrm{mM})$ was then added, and the reaction was left to stir for $15 \mathrm{~min}$. Particles were cleaned by centrifugation for $20 \mathrm{~min}$ at $3500 \mathrm{rpm}$ and concentrated in a $1 \mathrm{mM}$ sodium citrate solution to obtain a final concentration of $1 \mathrm{mM}$ $\mathrm{Au}^{0}$. The dispersion was kept in the fridge until further use.

\subsection{Fabrication of SERS Substrates}

Glass microscopy slides (Thermo Fisher Scientific, Bremen, Germany) were cleaned by soaking them $30 \mathrm{~min}$ in a piranha solution $\left(10 \mathrm{~mL}\right.$ of $\mathrm{H}_{2} \mathrm{O}_{2}$ with $30 \mathrm{~mL}$ of $\left.\mathrm{H}_{2} \mathrm{SO}_{4}\right)$, rinsing with MilliQ water, and drying with $\mathrm{N}_{2}$. Dried slides were then soaked in $40 \mathrm{~mL}$ of a $40 \mathrm{mg} / \mathrm{mL}$ solution of PAH for $15 \mathrm{~min}$. The excess polyelectrolyte was removed by rinsing the slides with MilliQ water and drying with $\mathrm{N}_{2}$ prior to a $4 \mathrm{~h}$ soak in $40 \mathrm{~mL}$ of AuNP dispersion. Finally, the Au-functionalized glass slides were rinsed with MilliQ water prior to drying in air at room temperature overnight. A $40 \mathrm{~mL}$ aliquot of $\mathrm{PAH}$ and $40 \mathrm{~mL}$ of AuNPs could be utilized to create a batch of $\sim 4$ glass slide substrates in one run; thus, multiple substrates were created and utilized for SERS measurements. In addition, substrates were created using three different batches of nanoparticles prepared on different weeks/months. 


\subsection{Characterization of AuNPs, PS and PET Particles, and SERS Substrates}

UV-vis extinction spectra of AuNPs in water were recorded at room temperature (RT) with a V-670 spectrophotometer (Jasco, Oklahoma City, OK, USA) using $10 \mathrm{~mm}$ path length quartz suprasil cuvettes (Hellma Analytics, Müllheim, Germany). To obtain UV-vis spectra of the substrates, baseline correction was performed with clean glass slides prior to the AuNP-functionalized glass slides being placed in the measurement pathway for spectra collection at RT.

A Tecnai Spirit transmission electron microscope (TEM, FEI, Columbia, MD, USA) operating at $120 \mathrm{kV}$ was used to image the AuNPs. A $10 \mu \mathrm{L}$ drop was cast onto carbon film on copper 300 square mesh (Electron Microscopy Sciences, Pennsylvania, PA, USA) and dried at RT before visualizing the particles with a $2048 \times 2048$ pixel wide angle Veleta CCD camera (Olympus, Toyko, Japan). TEM images were processed with the ImageJ software (v1.52). Average AuNP size and standard deviation were measured manually in Fiji (ImageJ, Wayne Rasband National Institute of Health, Bethesda, MD, USA [25]).

Hydrodynamic diameters and zeta potentials of the particles were measured using a 90Plus Particle Size Analyzer (Brookhaven Instruments Corporation, Holtsville, NY, USA) with phase-amplitude light scattering (PALS) for zeta-potential determination (Brookhaven Instruments, Holtsville, NY, USA) at an angle of $90^{\circ}$ with a $40 \mathrm{~mW}$ diode laser, $\lambda=640 \mathrm{~nm}$. The analysis was carried out in diluted suspensions in MilliQ water at RT. The hydrodynamic diameter of the PET particles was additionally obtained with a commercial goniometer instrument (3D LS Spectrometer, LS Instruments AG, Fribourg, Switzerland) by averaging multiple measurements taken in $10^{\circ}$ steps from $30^{\circ}$ to $150^{\circ}$ with 10 measurements of $30 \mathrm{~s}$ taken per angle. The stock concentration was measured through mass balancing with an OpenQCM quartz crystal microbalance (QCM; Novaetech S.r.l., Frascati, Italy).

PS and PET particles were imaged using a scanning electron microscope (SEM, TESCAN Mira 3 LM field emission, Kohoutovice, Czech Republic). Briefly, $10 \mu \mathrm{L}$ of diluted stock particles were dried on glass slides affixed to aluminum SEM stubs (Agar Scientific, Stansted, UK) with carbon black tape (Agar Scientific, Stansted, UK) and sputter coated with a $1 \mathrm{~nm}$ thick layer of gold using a $208 \mathrm{HR}$ sputter coater (Cressington Scientific Instruments, Watford, UK). Average particle size and standard deviation were measured manually in Fiji. AuNP substrates were also imaged with an SEM. Control images of clean substrates were obtained by mounting the slides to aluminum SEM stubs with carbon black tape. The edges of the mounted slides were coated with conductive silver paste (Plano $\mathrm{GmbH}$, Wetzlar, Germany) prior to sputter coating with a $1 \mathrm{~nm}$ thick layer of gold. Additional images were obtained in the same manner for the substrates once plastic particles were drop-cast onto their surface.

\subsection{Raman and SERS Spectroscopy}

All Raman and SERS measurements were conducted with a WiTec Alpha 300 R confocal Raman microscope operated with a $785 \mathrm{~nm}$ laser wavelength, a $50 \times$ magnification objective, and a built-in CCD camera for obtaining bright field images (WITec, Ulm, Germany). Individual SERS spectra were collected by accumulating multiple (i.e., 25-300) $1 \mathrm{~s}$ scans to generate a final, average spectra. Laser power ranged from $2 \mathrm{~mW}$ to $45 \mathrm{~mW}$ depending on the sample and the substrate used. Exact measurement details are given in Table A1. Automated SERS maps were collected by acquiring single $1 \mathrm{~s}$ spectra at multiple points within a defined region of interest (ROI). Laser power for mapping ranged from $2 \mathrm{~mW}$ to $7 \mathrm{~mW}$ depending on the sample. Confocal Raman image processing was conducted with the accompanying WITec Control 5 software, and all chemical fingerprint data was baseline corrected with this software (i.e., the measured background spectrum of each slide was subtracted from the sample data collected (Appendix A), a shape subtraction filter of 300 was applied, cosmic ray filters were applied). 


\subsection{Contamination Prevention}

In addition to washing glass slides with piranha to prevent contamination from previously deposited organic matter, slides were stored in closed containers during all procedural steps which did not directly involve their handling, and during the time between sample creation and analysis. (Disclaimer: piranha solution is a strong oxidizing substance and must be prepared with care.) When samples were handled, cotton lab coats and latex gloves were worn. All glassware was pre-washed prior to contact with a sample of interest.

\section{Results}

\subsection{SERS Substrates}

SEM images of the SERS substrates were successfully created via electrostatic layer-bylayer assembly utilizing a positively charged polyelectrolyte and negatively charged AuNPs in a manner that has been previously reported and validated in the literature [26-28]. Through soaking the glass slides in PAH and then in either citrate-stabilized $46 \mathrm{~nm}$ or $14 \mathrm{~nm}$ AuNPs, (see Figure A1 and Table 1 for the physicochemical characterization) a homogeneous distribution of the AuNPs on the final substrate could be obtained (Figure 1) [28]. The $46 \mathrm{~nm}$ AuNP substrate featured a plasmon band at $520 \mathrm{~nm}$ corresponding to the dipole resonance of individual AuNPs and two broad bands at 690, and $836 \mathrm{~nm}$ which correspond to the plasmon coupling between NPs in close proximity (Figure 1). Similarly, the $14 \mathrm{~nm}$ AuNP substrates exhibit two bands centered at 519 and 598 nm, respectively (Figure A2).

Table 1. Physicochemical characterization of the particles.

\begin{tabular}{cccc}
\hline & $\begin{array}{c}\text { Core Size } \\
(\mathbf{n m})\end{array}$ & $\begin{array}{c}\text { Hydrodynamic Diameter } \\
(\mathbf{n m})\end{array}$ & $\begin{array}{c}\text { Zeta Potential } \\
(\mathbf{m V})\end{array}$ \\
\hline $46 \mathrm{~nm}$ AuNPs & $46 \pm 5$ & $58 \pm 1$ & $-13.3 \pm 2.5$ \\
\hline $14 \mathrm{~nm}$ AuNPs & $14 \pm 1$ & $23 \pm 1$ & $-40.2 \pm 2.5$ \\
\hline $161 \mathrm{~nm}$ PS particles & $161 \pm 15$ & $192 \pm 4$ & $-45.1 \pm 2.3$ \\
\hline 33 nm PS particles & $33 \pm 6$ & $40 \pm 1$ & $-16.9 \pm 1.8$ \\
\hline $62 \mathrm{~nm} \mathrm{PET}^{1}$ particles & $62 \pm 38$ & $146 \pm 1$ & $-28.6 \pm 1.0$ \\
\hline
\end{tabular}

${ }^{1}$ Data adapted from Caldwell et al. Env. Sci.: Nano. 2021. [22]. ${ }^{2}$ Core sizes were obtained from electron microscopy measurements of at least 100 representative particles. For AuNPs a TEM was utilized. For plastic particles, a SEM was utilized.

PS particles in the sub-micron $(161 \pm 19 \mathrm{~nm})$ and the nano $(33 \pm 9 \mathrm{~nm})$ size range, in the following referred as to $161 \mathrm{~nm}$ PS and $33 \mathrm{~nm}$ PS particles, and PET particles with a core size of $62 \pm 38$ (Table 1), were cast onto the substrates and dried (Figures 1 and A3). In SEM images the plastic particles are observed to be distributed on the substrates following the "coffee-ring" effect (Figure A3); with a more homogenous layer of plastic particles present at the center of the dried sample drop surrounded by a ring of particle buildup. This was observed for all particles, down to the lowest concentrations studied and is an effect that has been studied extensively in the literature [29-31].

\subsection{SERS Detection of $161 \mathrm{~nm}$ PS, $33 \mathrm{~nm}$ PS, and $62 \mathrm{~nm}$ PET Particles}

Prior to characterizing the plastic particles by SERS, the Raman spectra of both PS and PET were taken by drop casting the stock solutions on a glass slide (Figure A4; Table A2). For PS, key peaks of interest are present as a result of ring breathing vibrations (i.e., $\mathrm{v}(\mathrm{C}-\mathrm{C})$ near $1002 \mathrm{~cm}^{-1}$ and $\beta(\mathrm{C}-\mathrm{H})$ near $\left.1032 \mathrm{~cm}^{-1}\right)$ of the benzenes within the polymer backbone [16]. Key peaks of interest for PET are known to be present at $1615-1620 \mathrm{~cm}^{-1}$ and $1730 \mathrm{~cm}^{-1}$ as a result of the ring breathing and carbonyl stretching, respectively $[9,31,32]$. 

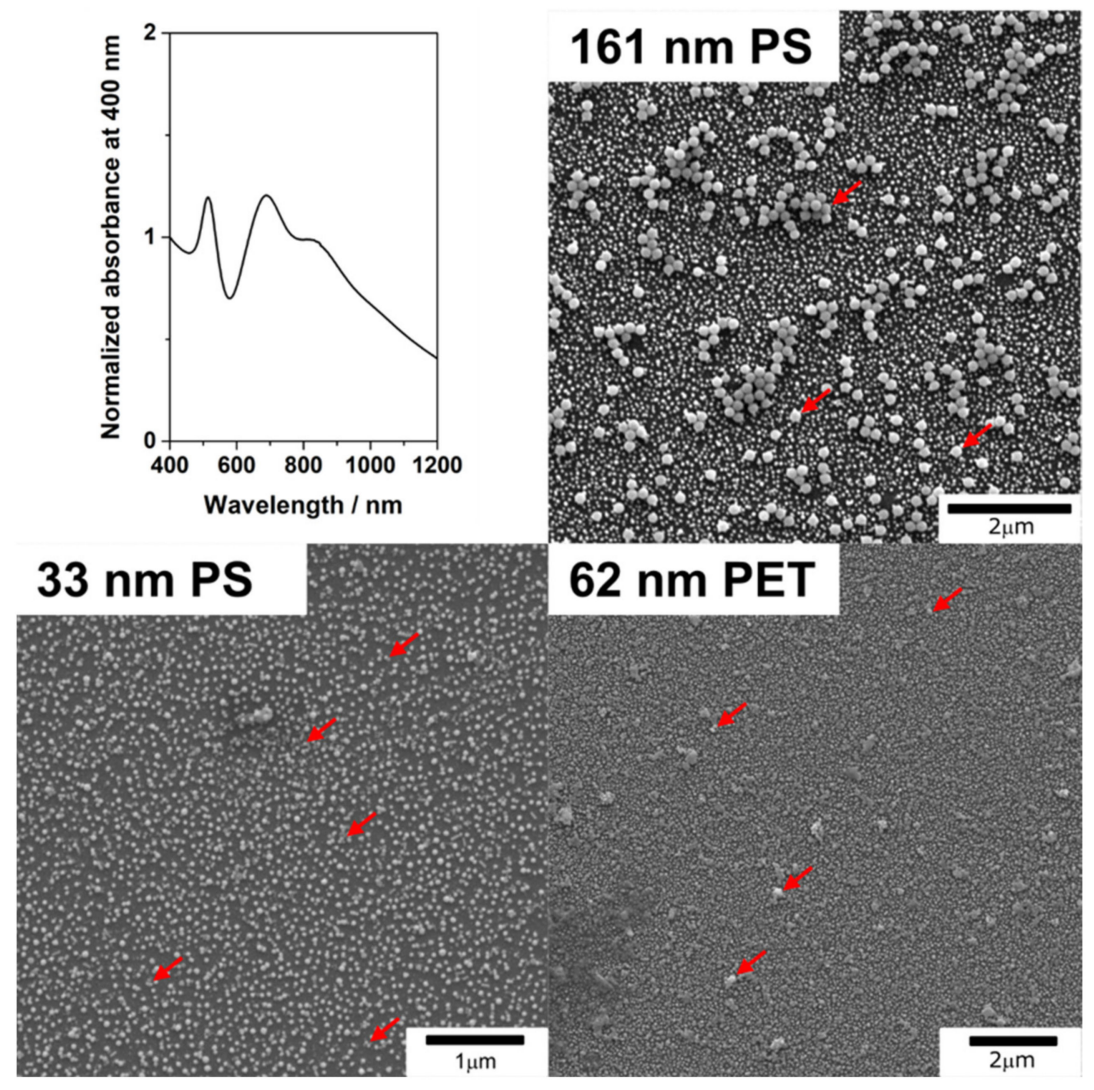

Figure 1. UV-vis extinction spectra of the $46 \mathrm{~nm}$ AuNP substrates and representative SEM images of the $161 \mathrm{~nm}$ PS, $33 \mathrm{~nm}$ PS, and $62 \mathrm{~nm}$ PET particles after their addition on top of the substrates. These images were taken at the middle of the cast drop and show that the gold and plastic particles are distributed homogenously throughout the substrate surface. Several examples of plastic particles are indicated with red arrows for clarity. See Figure A3 for additional SEM pictures.

After initial characterization, the plastic particle samples were analyzed using SERS. Sample concentrations examined for both the PS sub-microparticles $(161 \mathrm{~nm})$ and the PS nanoparticles $(33 \mathrm{~nm}$ ) included 100, 40,20, and $10 \mu \mathrm{g} / \mathrm{mL}$. Concentrations of 32 and $15 \mu \mathrm{g} / \mathrm{mL}$ of $62 \mathrm{~nm}$ PET particles were also analyzed.

The $161 \mathrm{~nm}$ PS and $33 \mathrm{~nm}$ PS samples on $46 \mathrm{~nm}$ (Figure 2) and $14 \mathrm{~nm}$ (Figure A5) AuNP substrates could be detected down to $20 \mu \mathrm{g} / \mathrm{mL}$ in the center of the cast droplet. Additionally, $161 \mathrm{~nm}$ PS could be detected at $10 \mu \mathrm{g} / \mathrm{mL}$ in areas of higher particle concentration (e.g., drop edge, particle aggregates or drying clusters) on the $46 \mathrm{~nm}$ AuNP substrates (Figure A6). During these measurements, substrates created using $14 \mathrm{~nm}$ AuNPs were shown to have weaker signal than those created using $46 \mathrm{~nm}$ AuNPs. Despite the lower enhancements, signal could still be detected on $14 \mathrm{~nm}$ AuNP substrates for both sizes of PS particles down to $20 \mu \mathrm{g} / \mathrm{mL}$ (Figure A5). It is important to note that signal for $33 \mathrm{~nm}$ PS particles on the $14 \mathrm{~nm}$ substrates was found only in regions with high concentration of PS particles (Figure A5). On the $14 \mathrm{~nm}$ AuNP substrates, it was not possible to detect $10 \mu \mathrm{g} / \mathrm{mL}$ of plastic particles even at areas of higher particle buildup. For all PS particles, the primary peak of interest used for their detection is present at $1002 \mathrm{~cm}^{-1}$ and at the higher sample concentrations (e.g., $100 \mu \mathrm{g} / \mathrm{mL}$ and $40 \mu \mathrm{g} / \mathrm{mL}$ of $161 \mathrm{~nm}$ PS), a weak peak at $1032 \mathrm{~cm}^{-1}$ can also be observed (Figure 2). Such findings are in good agreement with Raman control data (Figure A4) and findings reported in the literature [16,18]. 

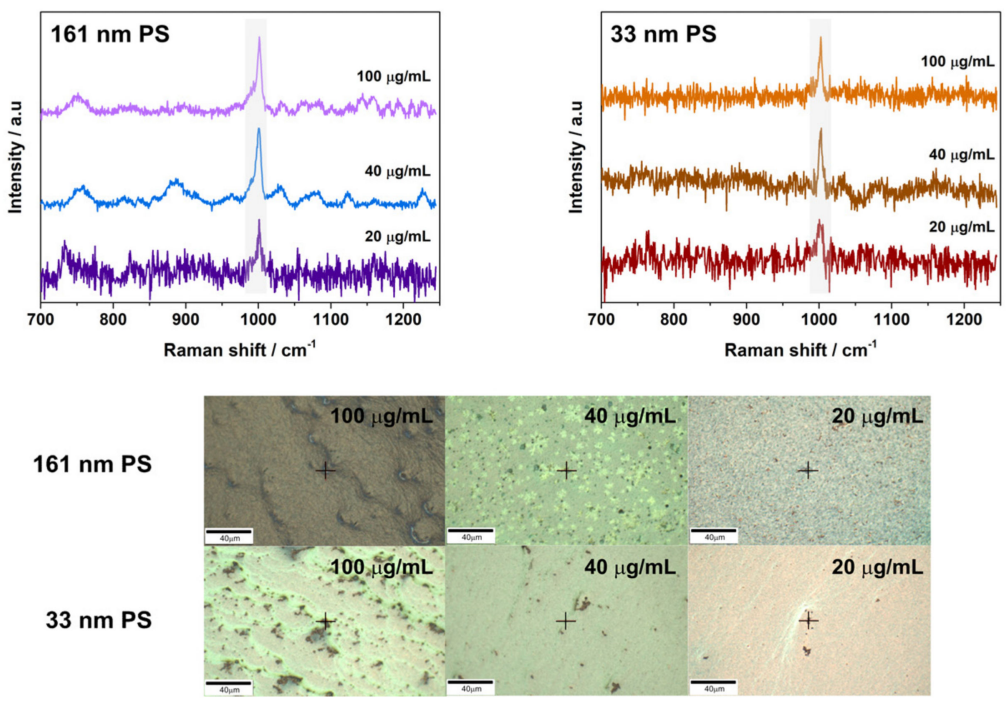

Figure 2. SERS spectra obtained for $161 \mathrm{~nm}$ PS particles on $46 \mathrm{~nm}$ AuNP substrates (top) and $33 \mathrm{~nm}$ PS nanoparticles on $46 \mathrm{~nm}$ AuNP substrates (bottom). Spectrum obtained are shown above images of the region of interest (ROI) the measurement was obtained from. Scale for all is $40 \mu \mathrm{m}$. Laser power, scan speeds, and number of averaged accumulations for the samples can be viewed in Table A1.

$32 \mu \mathrm{g} / \mathrm{mL}$ of $62 \mathrm{~nm}$ PET nanoparticles was detected with both $46 \mathrm{~nm}$ and $14 \mathrm{~nm}$ AuNP SERS substrates (Figures 3 and A7). Additionally, it was possible to detect PET nanoparticles on $46 \mathrm{~nm}$ substrates at a concentration of $15 \mu \mathrm{g} / \mathrm{mL}$ (Figure 3). However, for all PET samples the signal obtained was seen at regions of high particle build-up; indicating the limit of the substrates for PET particle detection was nearly reached during the measurements. This was confirmed when measurements with lower concentrations were attempted on both substrates, but no discernable PET signal could be detected.
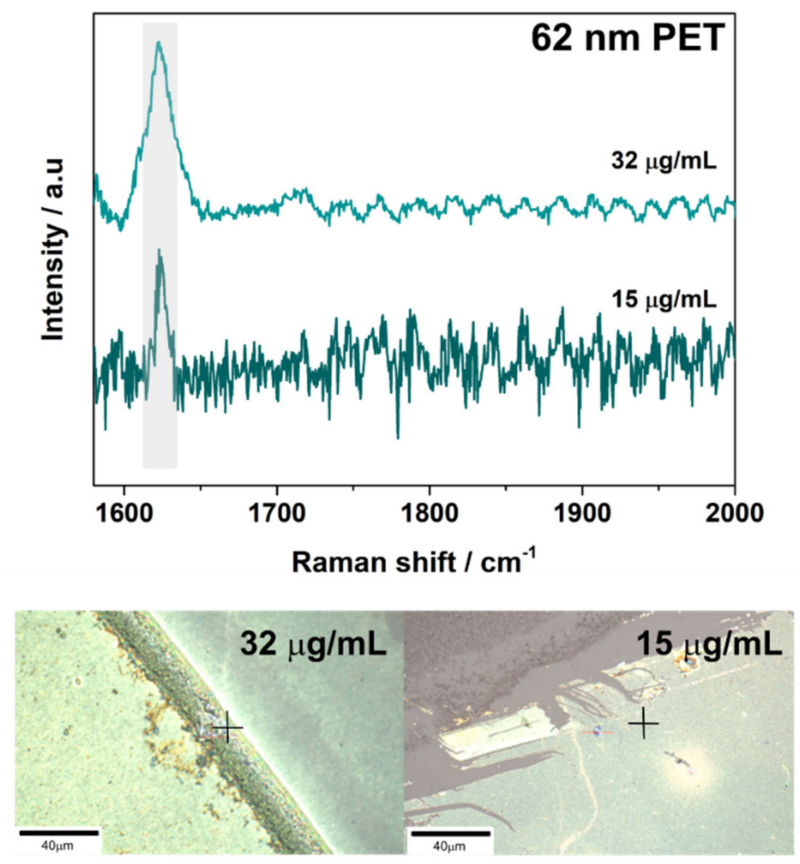

Figure 3. A representative SERS spectrum obtained for $62 \mathrm{~nm}$ PET nanoparticles on $46 \mathrm{~nm}$ AuNP substrates. The spectrum obtained is shown above images of the region of interest (ROI) the measurement was obtained from. Scale is $40 \mu \mathrm{m}$. Laser power, scan speeds, and number of averaged accumulations for the samples can be viewed in Table A1. 
To further investigate the SERS performance of the fabricated substrates, automated SERS mappings ( $37 \times 27 \mu \mathrm{m}$ ROI for $40 \mu \mathrm{g} / \mathrm{mL}$ of $33 \mathrm{~nm}$ PS; $45 \times 30 \mu \mathrm{m}$ ROI for $100 \mu \mathrm{g} / \mathrm{mL}$ of $33 \mathrm{~nm}$ PS; $39 \times 28 \mu \mathrm{m}$ ROI for $40 \mu \mathrm{g} / \mathrm{mL}$ of $161 \mathrm{~nm}$ PS; $53 \times 46 \mu \mathrm{m}$ ROI for $100 \mu \mathrm{g} / \mathrm{mL}$ of $161 \mathrm{~nm}$ PS) for the $785 \mathrm{~nm}$ excitation laser line were performed by recording the SERS intensity at the ring breathing peak of the PS at $1002 \mathrm{~cm}^{-1}$. As shown in Figures 4 and A8, the signal intensity obtained in the investigated area is uniform and homogeneous.

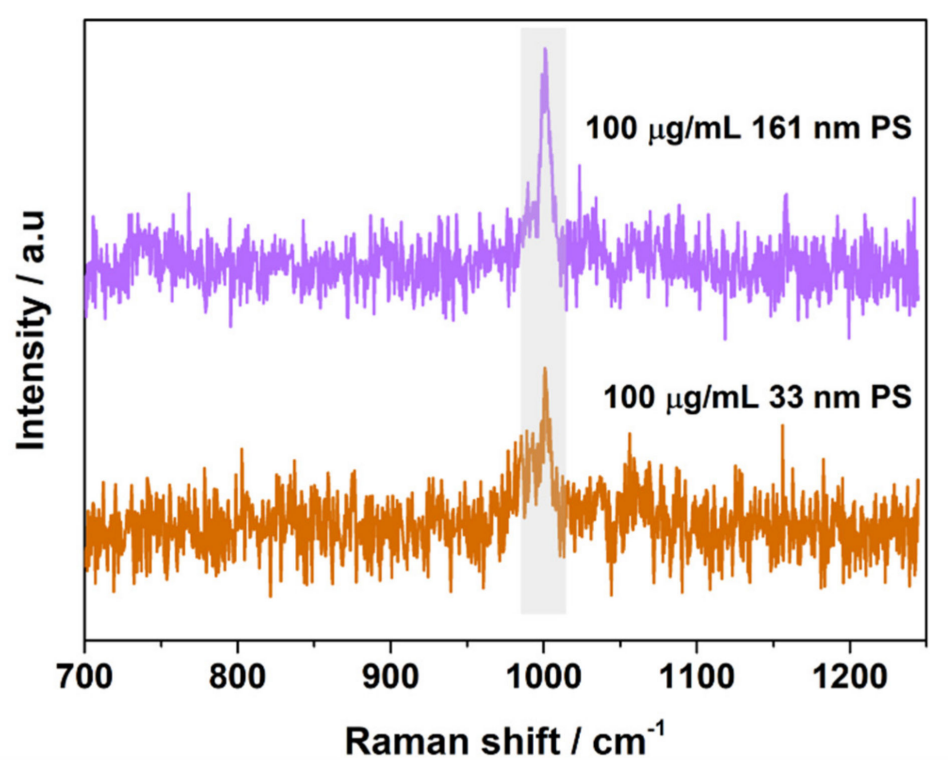

$161 \mathrm{~nm}$ PS

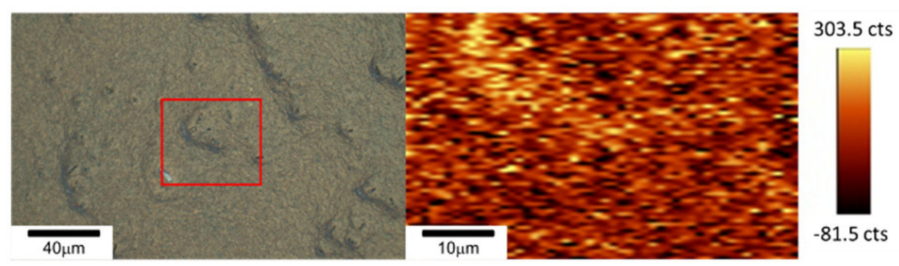

\section{$33 \mathrm{~nm}$ PS}
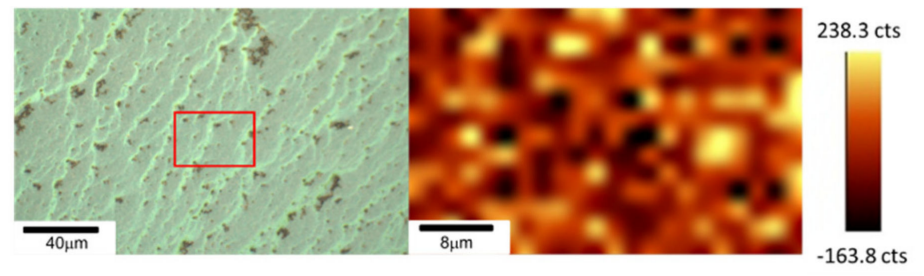

Figure 4. Representative SERS spectra obtained through automated mapping for $100 \mu \mathrm{g} / \mathrm{mL}$ samples of $161 \mathrm{~nm}$ PS particles on $46 \mathrm{~nm}$ AuNP substrates and samples of $100 \mu \mathrm{g} / \mathrm{mL}$ of $33 \mathrm{~nm}$ PS nanoparticles on $46 \mathrm{~nm}$ AuNP substrates. Laser power, scan speeds, and number of averaged accumulations for the samples can be viewed in Table A1. Spectrum obtained are shown above images of the intensity maps for the PS peak at $1002 \mathrm{~cm}^{-1}$ and the regions of interest (ROIs) the measurement was obtained from. Spectra come from regions of high intensity for the peak at $1002 \mathrm{~cm}^{-1}$.

It is important to note that no Raman signal was detected for any of the plastic particles at the studied concentrations when they were dried on plain glass; even when areas of high particle concentration (e.g., the sample edge, plastic particle aggregates or drying clusters) were measured. For this comparison, Raman spectra were obtained under conditions comparable to those reported for the SERS measurements (Figure A9). Additionally, the SERS spectra of the plastic particles showed distinct differences from SERS spectra obtained for the substrates alone (Figure A10). 


\subsection{Analytical Enhancement Factor (AEF)}

Once SERS spectral data was collected for every sample, the signals obtained could be compared to the control Raman spectra for plastic particles on plain glass (Figure A9). This comparison was done through calculation of the analytical enhancement factor (AEF) achieved for each sample on both types of substrates [32]. The calculation was done using the $1002 \mathrm{~cm}^{-1}$ peak (for PS) and the $1617 \mathrm{~cm}^{-1}$ peak (for PET) intensity (I) and the sample concentration $(C)$ both for SERS spectra (ISERS and $\left.C_{S E R S}\right)$ and their accompanying Raman control spectra ( $I_{\text {Raman }}$ and $C_{\text {Raman }}$ ) as shown in Equation (1):

$$
\mathrm{AEF}=\frac{\frac{I_{\text {SERS }}}{C_{\text {SERS }}} / \frac{I_{\text {Raman }}}{C_{\text {Raman }}}}{}
$$

The highest overall AEF was 446 for the $161 \mathrm{~nm}$ PS on $46 \mathrm{~nm}$ AuNP substrates. For comparison, the highest enhancement obtained for $161 \mathrm{~nm}$ PS on $14 \mathrm{~nm}$ AuNP substrates was 360. The highest AEF for PET (i.e., 185) was also obtained with the $46 \mathrm{~nm}$ AuNP substrates. The $33 \mathrm{~nm}$ PS particle samples were the only ones to have the highest AEF (i.e., 127) on the $14 \mathrm{~nm}$ AuNP substrates. A complete summary of the AEFs for each sample measured can be found in Table 2 .

Table 2. A summary of analytical enhancement factors (AEFs) calculated for each sample.

\begin{tabular}{ccc}
\hline & AEF on $\mathbf{4 6} \mathbf{~ n m}$ AuNPs & AEF on 14 nm AuNPs \\
\hline $100 \mu \mathrm{g} / \mathrm{mL}$ of $161 \mathrm{~nm}$ PS & 63.6 & 23.2 \\
\hline $40 \mu \mathrm{g} / \mathrm{mL}$ of $161 \mathrm{~nm}$ PS & 445.7 & 50.9 \\
\hline $20 \mu \mathrm{g} / \mathrm{mL}$ of $161 \mathrm{~nm}$ PS & 380.0 & 360.0 \\
\hline $10 \mu \mathrm{g} / \mathrm{mL}$ of $161 \mathrm{~nm}$ PS & 37.0 & - \\
\hline $100 \mu \mathrm{g} / \mathrm{mL}$ of $33 \mathrm{~nm}$ PS & 97.5 & 13.6 \\
\hline $40 \mu \mathrm{g} / \mathrm{mL}$ of $33 \mathrm{~nm}$ PS & 53.1 & 23.0 \\
\hline $20 \mu \mathrm{g} / \mathrm{mL}$ of $33 \mathrm{~nm}$ PS & 56.7 & 126.7 \\
\hline $32 \mu \mathrm{g} / \mathrm{mL}$ of $62 \mathrm{~nm}$ PET & 185.4 & 63.1 \\
\hline $15 \mu \mathrm{g} / \mathrm{mL}$ of 62 PET & 32.8 & - \\
\hline
\end{tabular}

\section{Discussion and Conclusions}

Through the analysis of plastic particle samples at various concentrations, it was shown that the $46 \mathrm{~nm}$ AuNP substrates could detect plastics in samples at lower concentrations than what was possible for the $14 \mathrm{~nm}$ AuNP substrates-likely as a result of the increased plasmon bandwidth at increasing AuNP size [33,34]. Thus, the final limits presented for $46 \mathrm{~nm}$ AuNP substrates are $10 \mu \mathrm{g} / \mathrm{mL}$ for the $161 \mathrm{~nm}$ PS, $20 \mu \mathrm{g} / \mathrm{mL}$ for the $33 \mathrm{~nm}$ PS, and $15 \mu \mathrm{g} / \mathrm{mL}$ for the $62 \mathrm{~nm}$ PET while the sample concentrations that can be analyzed with the $14 \mathrm{~nm}$ AuNP substrates are $20 \mu \mathrm{g} / \mathrm{mL}$ for the $161 \mathrm{~nm}$ PS and the $33 \mathrm{~nm}$ PS, and $32 \mu \mathrm{g} / \mathrm{mL}$ for the $62 \mathrm{~nm}$ PET (Table 2). AEF calculation also revealed that the $46 \mathrm{~nm}$ AuNP substrates provided higher signal enhancement when compared to $14 \mathrm{~nm}$ AuNP substrates; with maximum AEF for $46 \mathrm{~nm}$ AuNP substrates being 446 while the maximum AEF for $14 \mathrm{~nm}$ AuNP substrates was 360. This trend is in good agreement with findings previously reported in the literature by groups like Joseph et al. and Zhu et al. [33,35]. Briefly, these two research groups compared the enhancement factors obtained from various sizes of AuNPs; either in dispersion or once they were immobilized on silicon surfaces; and reported an increase in enhancement factor with increasing AuNP size [33,35]. This trend is linked directly to the ability of the AuNPs to scatter light and to the availability of electrons present on the gold surface. Particles below a certain size have surface interactions which become dominated by electronic scattering processes in a manner that diminishes the re-radiated electromagnetic energy and, therefore, the overall SERS signal generated [36]. 
Additionally, the number of electrons present on the metal surface, and therefore SERS signal, increases with increasing particle size until the size is within a regime comparable to that of the light wavelength used to excite it; at which point only non-radiative plasmon modes are excited [36].

Furthermore, the AEF values reported in this study are comparable to those reported for plastic particles analyzed with other SERS substrates; Xu et al. reported enhancements of up to 2 orders of magnitude for single spherical sub-microplastic particles (i.e., $360 \mathrm{~nm}$ ) composed of PET, PMMA, or PS on Klarite substrates while Lv et al. reported AgNPs could be used to detect $100 \mathrm{~nm}$ PS particles down to $40 \mu \mathrm{g} / \mathrm{mL}$ with AEFs up to 500 [16,18]. In addition to the comparable AEF values, the SERS substrates created in the present study could be used to detect smaller sub-microplastic particles (i.e., $161 \mathrm{~nm}$ PS) and nanoparticles (i.e., $33 \mathrm{~nm}$ PS or $62 \mathrm{~nm}$ PET) at lower concentrations (i.e., down to $10 \mu \mathrm{g} / \mathrm{mL}$ ) than what has previously been reported in the literature. For samples with concentrations of $40 \mu \mathrm{g} / \mathrm{mL}$ or higher, the substrates created in this study could be used in automated area scan measurements to generate intensity maps that gave insight into the spatial distribution of the plastic particles.

While it was possible to detect even highly heterogenous nanoplastic particles obtained from milling, the substrates presented herein have not yet been tested for use in the detection of plastics directly within more complex sample matrices (i.e., foods or environmental samples) that would be more relevant to current micro-, sub-micro-, and nanoplastic studies. Thus, future research should consider the analysis of such samples. Additionally, while the concentrations utilized within this study fall within the ranges reported for use in in-vivo laboratory studies conducted with $\sim 70 \mathrm{~nm}$ PS nanoparticles (i.e., $155 \mathrm{mg} / \mathrm{L}-32 \mathrm{mg} / \mathrm{L}$ ) they are not yet as low as the roughly $1 \mu \mathrm{g} / \mathrm{L}-1 \mathrm{ng} / \mathrm{L}$ values predicted for environmental samples [6,37]. Thus, further consideration should also be given to the potential use of AuNPs with varying shapes (e.g., rods, stars) that may provide additional signal enhancement $[19,38]$. However, this study stands as a proof-of-concept for the detection of nanoplastic particles through the use of SERS substrates created using colloidal AuNPs.

Author Contributions: J.C. was responsible for substrate creation, acquisition and interpretation of data, and writing; P.T.-B. was the head co-investigator and responsible for method creation and validation, some data acquisition and interpretation, and editing; B.R.-R. was responsible for editing; A.P.-F. was responsible for editing and was the project's principal investigator. All authors have read and agreed to the published version of the manuscript.

Funding: J.C. and A.P.-F. acknowledge funding from the Swiss National Science Foundation (200020_184635). All authors would like to thank the Adolphe Merkle Foundation for providing funding. Additionally, this work benefitted from support from the Swiss National Science Foundation through the National Center of Competence in Research Bio-Inspired Materials.

Data Availability Statement: All raw data used to create the presented figures and tables can be found at http:/ / doi.org/10.5281/zenodo.4722747 (accessed on 27 April 2021).

Acknowledgments: The authors would like to thank Laetitia Haeni and Liliane Ackermann Hirschi for their support with particle synthesis as well as collaborators at FREWITT fabrique de machines SA (Granges-Paccot, Switzerland) for allowing access to the mill required to create the PET nanoparticles.

Conflicts of Interest: The authors declare no conflict of interest. The funders had no role in the design of the study; in the collection, analyses, or interpretation of data; in the writing of the manuscript, or in the decision to publish the results. 
Appendix A. Expanded Characterization Details
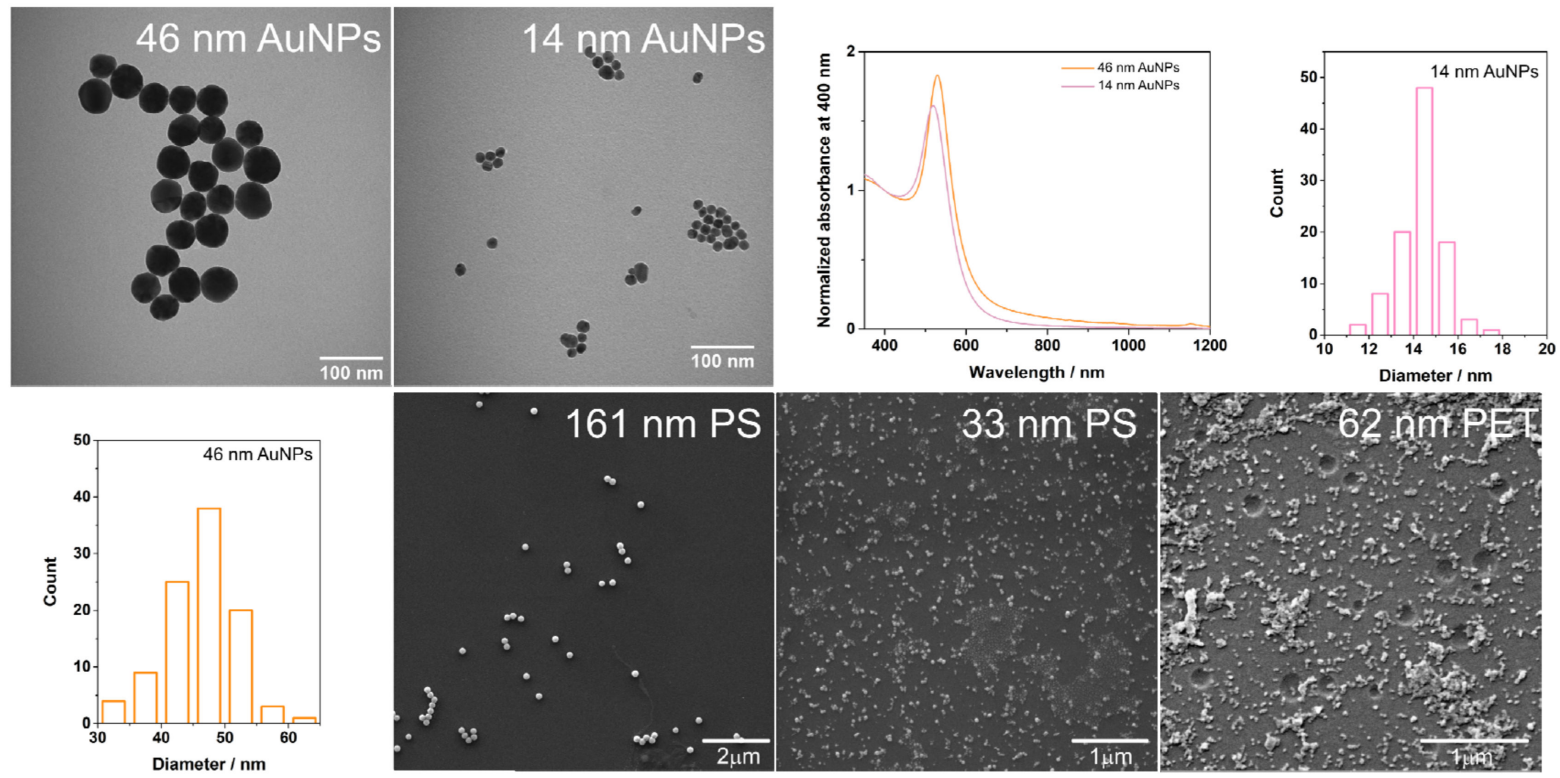

Figure A1. UV-vis extinction spectra for the stock AuNP dispersions are shown alongside representative TEM images for the $46 \mathrm{~nm}$ gold and the $14 \mathrm{~nm}$ gold stock particles as well as histograms of their sizing data. SEM images for the $161 \mathrm{~nm}$ PS, the $33 \mathrm{~nm}$ PS, and the PET are also shown.

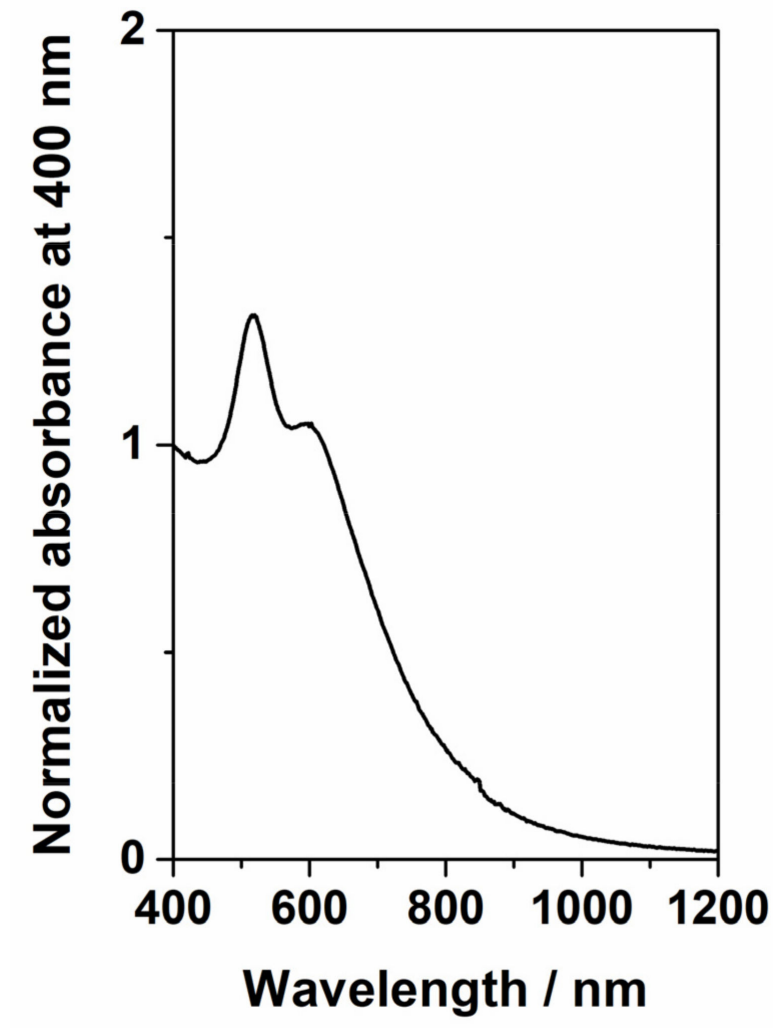

Figure A2. Representative extinction spectra for the $14 \mathrm{~nm}$ AuNP substrates. 

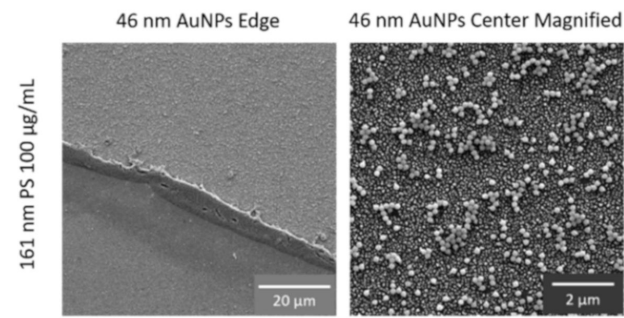

$14 \mathrm{~nm}$ AuNPs Edge

$14 \mathrm{~nm}$ AuNPs Center Magnified
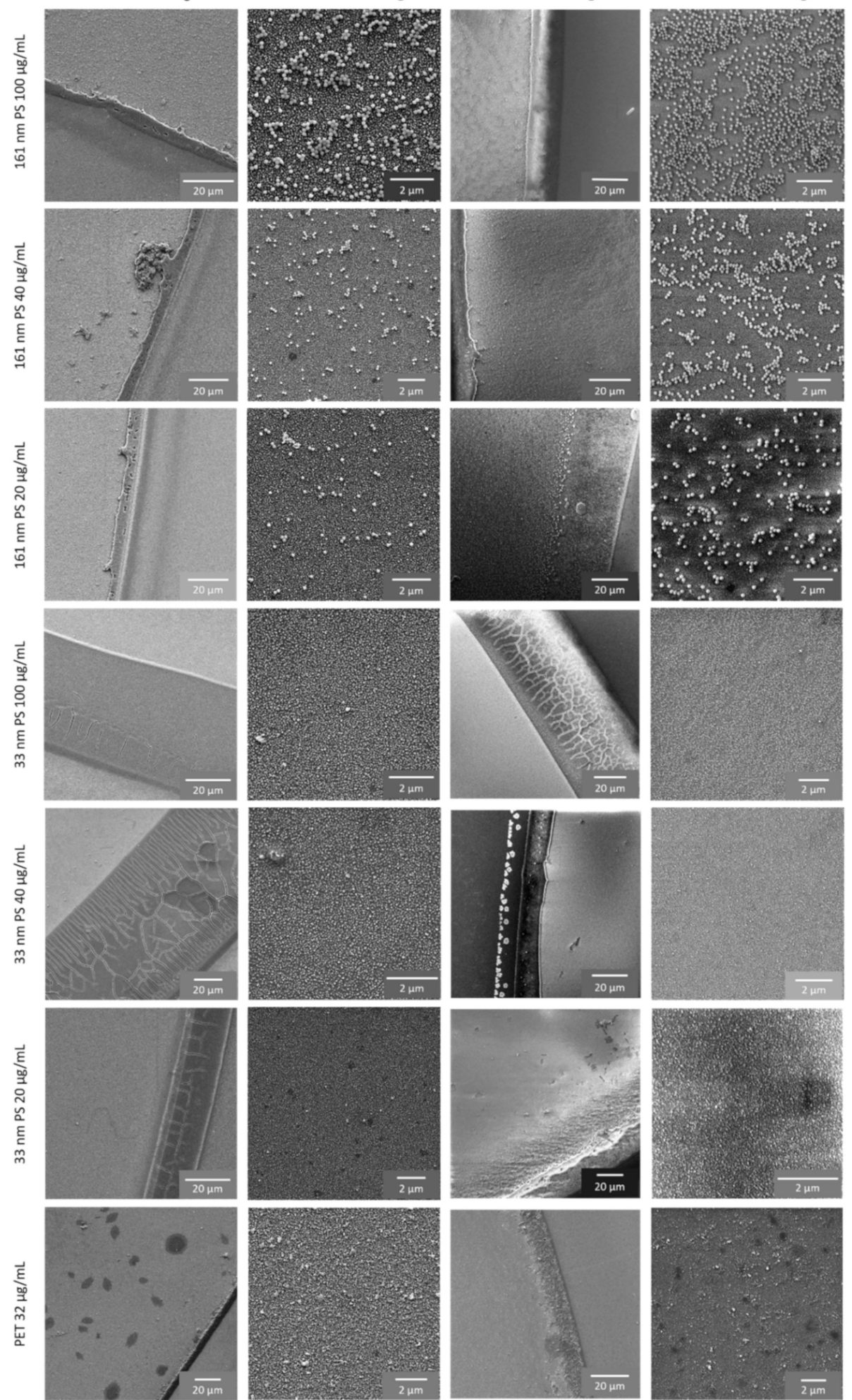

Figure A3. SEM images for the final, dried plastic particle samples on the SERS substrates. Image columns are labelled with the gold nanoparticle type used to create the substrate. Image rows are labelled with the type of plastic particle sample represented. $20 \mu \mathrm{m}$ scale images show the dried edge of the plastic samples. $2 \mu \mathrm{m}$ images are obtained from the sample centers. 

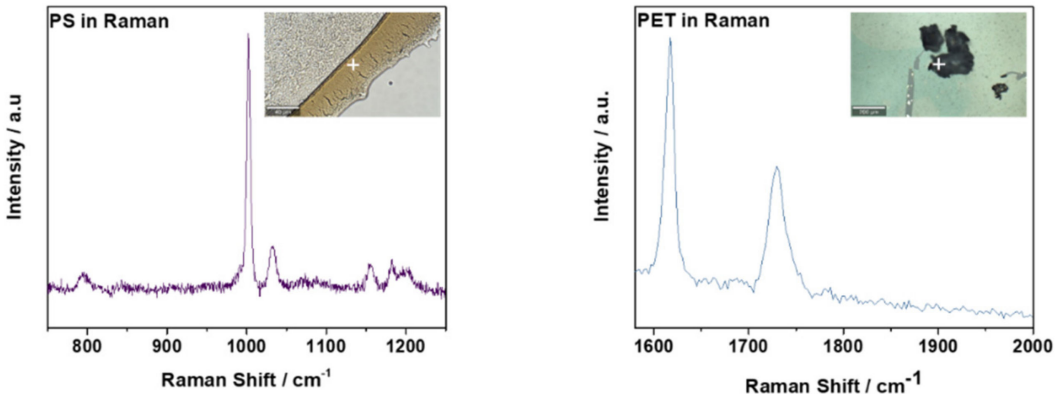

Figure A4. Representative Raman spectra measured for $161 \mathrm{~nm}$ PS sub-microparticles which were drop-cast in layers until a thick enough deposition was achieved to obtain a Raman signal $(100 \times$ magnification; scale bar $40 \mu \mathrm{m}$ ) (left) and for stock milled PET microparticles (average size <170 $\mu \mathrm{m}$ [22]; scale bar $200 \mu \mathrm{m}$ ). Laser power, scan speeds, and number of averaged accumulations for the samples can be viewed in Table A1. Spectrum obtained are shown with the region of interest (ROI) the measurement was obtained from.
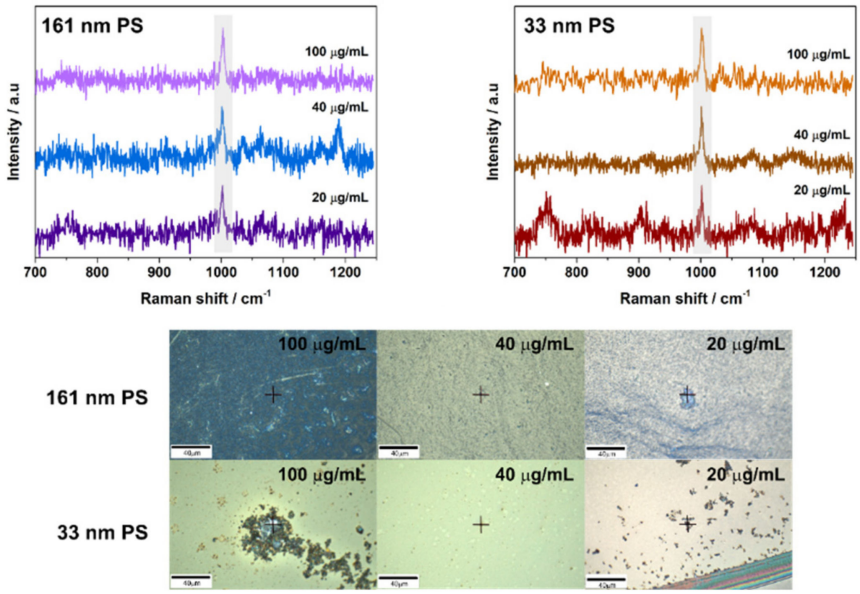

Figure A5. SERS spectra obtained for $161 \mathrm{~nm}$ PS particles on $14 \mathrm{~nm}$ AuNP substrates as well as the $33 \mathrm{~nm}$ PS nanoparticles on $14 \mathrm{~nm}$ AuNP substrates. Spectrum obtained are shown above images of the region of interest (ROI) the measurement was obtained from. Scale for all is $40 \mu \mathrm{m}$. Laser power, scan speeds, and number of averaged accumulations for the samples can be viewed in Table A1.

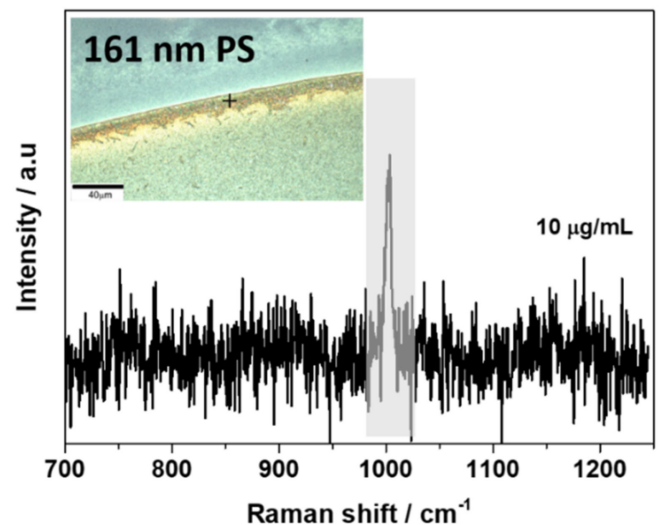

Figure A6. SERS spectra obtained for $10 \mu \mathrm{g} / \mathrm{mL}$ of $161 \mathrm{~nm}$ PS particles on $46 \mathrm{~nm}$ AuNP substrates. The spectrum is shown with an image of the region of interest (ROI) the measurement was obtained from. Scale is $40 \mu \mathrm{m}$. Laser power, scan speeds, and number of averaged accumulations for the samples can be viewed in Table A1. 
Table A1. A summary of measurement parameters utilized to obtain the final spectra presented for each sample.

\begin{tabular}{|c|c|c|c|c|}
\hline Sample & Substrate & $\begin{array}{l}\text { Laser Power } \\
\quad(\mathrm{mW})\end{array}$ & $\begin{array}{l}\text { Scan Speed } \\
\text { (s) }\end{array}$ & $\begin{array}{c}\text { Number of } \\
\text { Accumulations }\end{array}$ \\
\hline 161 nm PS Raman Control & Glass & 40 & 1 & 60 \\
\hline $100 \mu \mathrm{g} / \mathrm{mL}$ of $161 \mathrm{~nm}$ PS & $46 \mathrm{~nm}$ AuNPs & 7 & 1 & 300 \\
\hline $100 \mu \mathrm{g} / \mathrm{mL}$ of $161 \mathrm{~nm}$ PS-Mapping & $46 \mathrm{~nm}$ AuNPs & 7 & 1 & - \\
\hline $100 \mu \mathrm{g} / \mathrm{mL}$ of $161 \mathrm{~nm}$ PS & $14 \mathrm{~nm}$ AuNPs & 5 & 1 & 40 \\
\hline $100 \mu \mathrm{g} / \mathrm{mL}$ of $161 \mathrm{~nm}$ PS & Glass & 45 & 1 & 50 \\
\hline $40 \mu \mathrm{g} / \mathrm{mL}$ of $161 \mathrm{~nm}$ PS & $46 \mathrm{~nm}$ AuNPs & 7 & 1 & 100 \\
\hline $40 \mu \mathrm{g} / \mathrm{mL}$ of $161 \mathrm{~nm}$ PS-Mapping & $46 \mathrm{~nm}$ AuNPs & 4 & 1 & - \\
\hline $40 \mu \mathrm{g} / \mathrm{mL}$ of $161 \mathrm{~nm}$ PS & $14 \mathrm{~nm}$ AuNPs & 4 & 1 & 40 \\
\hline $40 \mu \mathrm{g} / \mathrm{mL}$ of $161 \mathrm{~nm}$ PS & Glass & 7 & 1 & 50 \\
\hline $20 \mu \mathrm{g} / \mathrm{mL}$ of $161 \mathrm{~nm}$ PS & $46 \mathrm{~nm}$ AuNPs & 12 & 1 & 100 \\
\hline $20 \mu \mathrm{g} / \mathrm{mL}$ of $161 \mathrm{~nm}$ PS & $14 \mathrm{~nm}$ AuNPs & 12 & 1 & 100 \\
\hline $20 \mu \mathrm{g} / \mathrm{mL}$ of $161 \mathrm{~nm}$ PS & Glass & 15 & 1 & 100 \\
\hline $10 \mu \mathrm{g} / \mathrm{mL}$ of $161 \mathrm{~nm}$ PS & $46 \mathrm{~nm}$ AuNPs & 7 & 1 & 100 \\
\hline $10 \mu \mathrm{g} / \mathrm{mL}$ of $161 \mathrm{~nm}$ PS & Glass & 45 & 1 & 100 \\
\hline $100 \mu \mathrm{g} / \mathrm{mL}$ of $33 \mathrm{~nm}$ PS & $46 \mathrm{~nm}$ AuNPs & 2 & 1 & 25 \\
\hline $100 \mu \mathrm{g} / \mathrm{mL}$ of $33 \mathrm{~nm}$ PS-Mapping & $46 \mathrm{~nm}$ AuNPs & 2 & 1 & - \\
\hline $100 \mu \mathrm{g} / \mathrm{mL}$ of $33 \mathrm{~nm}$ PS & $14 \mathrm{~nm}$ AuNPs & 20 & 1 & 100 \\
\hline $100 \mu \mathrm{g} / \mathrm{mL}$ of $33 \mathrm{~nm}$ PS & Glass & 2 & 1 & 50 \\
\hline $40 \mu \mathrm{g} / \mathrm{mL}$ of $33 \mathrm{~nm}$ PS & $46 \mathrm{~nm}$ AuNPs & 2 & 1 & 50 \\
\hline $40 \mu \mathrm{g} / \mathrm{mL}$ of $33 \mathrm{~nm}$ PS-Mapping & $46 \mathrm{~nm}$ AuNPs & 2 & 1 & - \\
\hline $40 \mu \mathrm{g} / \mathrm{mL}$ of $33 \mathrm{~nm}$ PS & $14 \mathrm{~nm}$ AuNPs & 7 & 1 & 25 \\
\hline $40 \mu \mathrm{g} / \mathrm{mL}$ of $33 \mathrm{~nm}$ PS & Glass & 2 & 1 & 50 \\
\hline $20 \mu \mathrm{g} / \mathrm{mL}$ of $33 \mathrm{~nm}$ PS & $46 \mathrm{~nm}$ AuNPs & 15 & 1 & 100 \\
\hline $20 \mu \mathrm{g} / \mathrm{mL}$ of $33 \mathrm{~nm}$ PS & $14 \mathrm{~nm}$ AuNPs & 10 & 1 & 100 \\
\hline $20 \mu \mathrm{g} / \mathrm{mL}$ of $33 \mathrm{~nm}$ PS & Glass & 45 & 1 & 100 \\
\hline PET Microparticle Raman Control & Glass & 30 & 1 & 25 \\
\hline $32 \mu \mathrm{g} / \mathrm{mL}$ of $62 \mathrm{~nm}$ PET & $46 \mathrm{~nm}$ AuNPs & 10 & 1 & 100 \\
\hline $32 \mu \mathrm{g} / \mathrm{mL}$ of $62 \mathrm{~nm}$ PET & $14 \mathrm{~nm}$ AuNPs & 8 & 1 & 50 \\
\hline $32 \mu \mathrm{g} / \mathrm{mL}$ of $62 \mathrm{~nm}$ PET & Glass & 45 & 1 & 100 \\
\hline $15 \mu \mathrm{g} / \mathrm{mL}$ of $62 \mathrm{PET}$ & $46 \mathrm{~nm}$ AuNPs & 7 & 1 & 100 \\
\hline $15 \mu \mathrm{g} / \mathrm{mL}$ of 62 PET & Glass & 45 & 1 & 100 \\
\hline $\begin{array}{l}\text { Glass Slide Only Control-Raman Shift } \\
\qquad 700-1250 \mathrm{~cm}^{-1}\end{array}$ & - & 7 & 1 & 50 \\
\hline $\begin{array}{l}\text { Slide@PAH@46nmAu Control-Raman Shift } \\
\text { 700-1250 cm }{ }^{-1}\end{array}$ & - & 7 & 1 & 50 \\
\hline $\begin{array}{l}\text { Slide@PAH@14nmAu Control-Raman Shift } \\
\text { 700-1250 cm } \text { cm }^{-1}\end{array}$ & - & 7 & 1 & 50 \\
\hline $\begin{array}{l}\text { Glass Slide Only Control-Raman Shift } \\
\qquad 1580-2000 \mathrm{~cm}^{-1}\end{array}$ & - & 12 & 1 & 100 \\
\hline $\begin{array}{l}\text { Slide@PAH@46nmAu Control-Raman Shift } \\
\text { 1580-2000 cm }{ }^{-1}\end{array}$ & - & 7 & 1 & 50 \\
\hline $\begin{array}{l}\text { Slide@PAH@14nmAu Control-Raman Shift } \\
\text { 1580-2000 cm } \text { ch }^{-1}\end{array}$ & - & 7 & 1 & 50 \\
\hline
\end{tabular}


Table A2. Summary of the vibrational band assignments for PS and PET.

\begin{tabular}{ccc}
\hline & Raman Shift $\mathbf{( \mathbf { c m } ^ { - 1 } )}$ & Assignment \\
\hline \multirow{2}{*}{ PS } & $\sim 1002$ & C-C ring breathing mode [16] \\
\cline { 2 - 3 } & $\sim 1032$ & C-H in-plane deformation, $\beta(\mathrm{C}-\mathrm{H})[16]$ \\
\hline \multirow{2}{*}{ PET } & $\sim 1615-1620$ & Aromatic bending vibrations $[8,39]$ \\
\hline
\end{tabular}

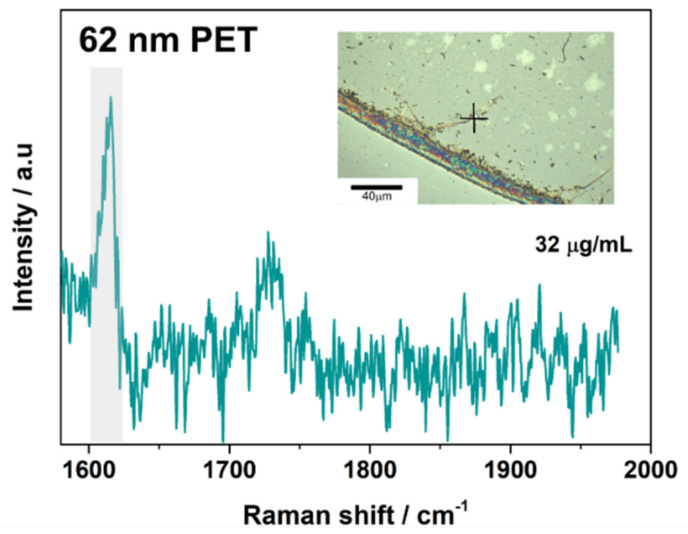

Figure A7. A Representative SERS spectrum obtained for $62 \mathrm{~nm}$ PET nanoparticles on $14 \mathrm{~nm}$ AuNP substrates. The spectrum is shown with an image of the region of interest (ROI) the measurement was obtained from. Scale is $40 \mu \mathrm{m}$. Laser power, scan speeds, and number of averaged accumulations for the samples can be viewed in Table A1.
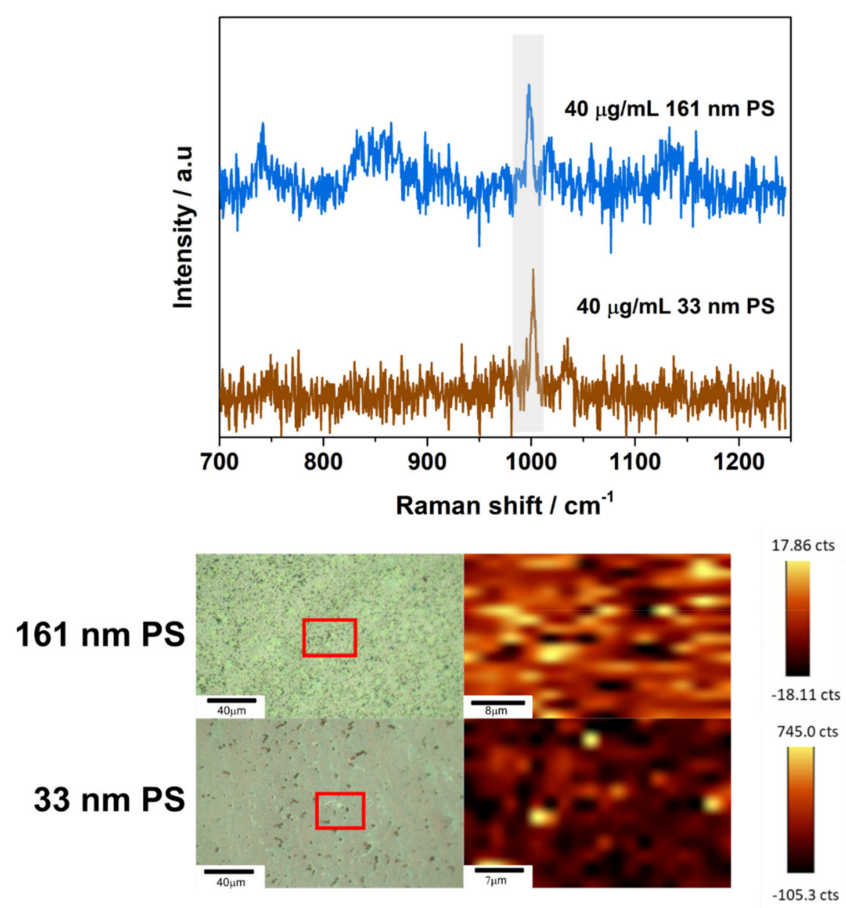

Figure A8. Additional representative SERS spectra obtained through automated mapping for $40 \mu \mathrm{g} / \mathrm{mL}$ samples of $161 \mathrm{~nm}$ PS particles on $46 \mathrm{~nm}$ AuNP substrates and $40 \mu \mathrm{g} / \mathrm{mL}$ samples of $33 \mathrm{~nm}$ PS nanoparticles on $46 \mathrm{~nm}$ AuNP substrates. Laser power, scan speeds, and number of averaged accumulations for the samples can be viewed in Table A1. Spectrum obtained are shown above images of the intensity maps for the PS peak at $1002 \mathrm{~cm}^{-1}$ and the regions of interest (ROIs) the measurement was obtained from. Spectra come from regions of high intensity for the peak at $1002 \mathrm{~cm}^{-1}$. 

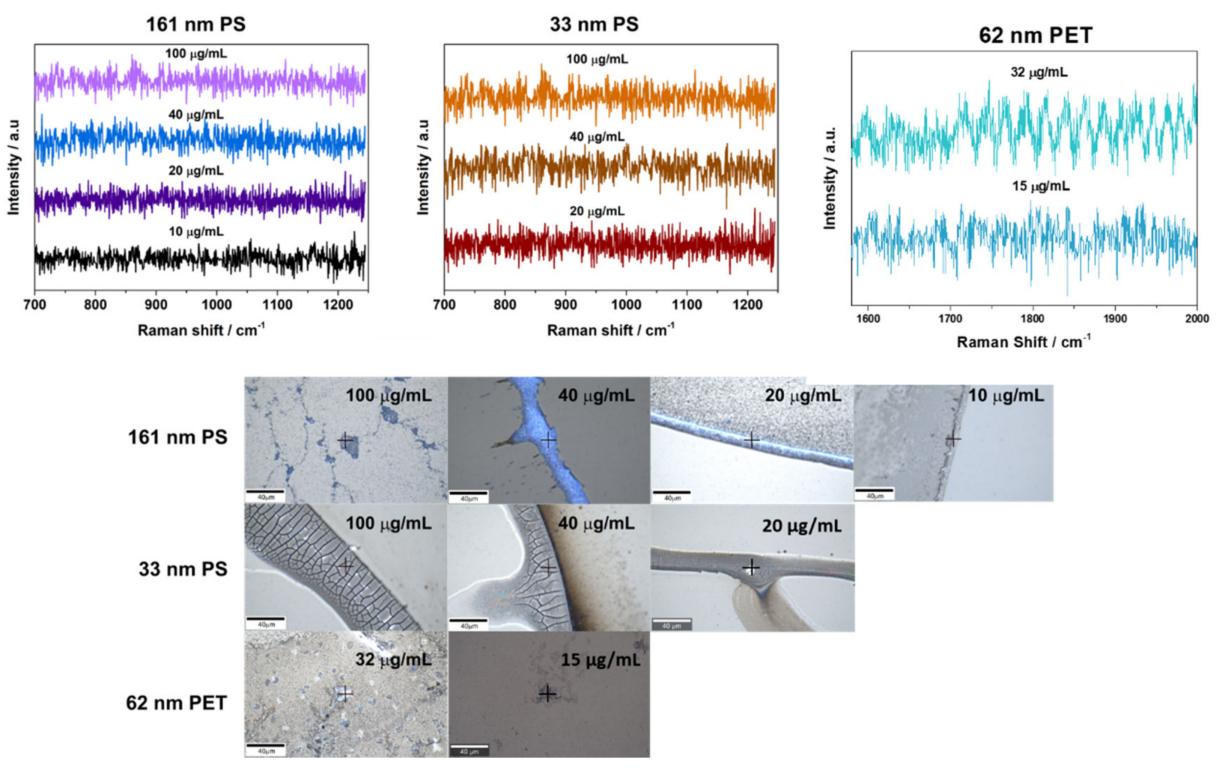

Figure A9. Representative Raman spectra obtained for $161 \mathrm{~nm}$ PS particles on plain glass and 33 nm PS nanoparticles on plain glass. Spectra obtained are shown above images of the region of interest (ROI) the measurement was obtained from. The images are labelled with the relevant sample information. Scale for all is $40 \mu \mathrm{m}$. Laser power, scan speeds, and number of averaged accumulations for the samples can be viewed in Table A1. Additionally, representative Raman spectrum obtained for PET nanoparticles on plain glass is shown. Scale is $40 \mu \mathrm{m}$.
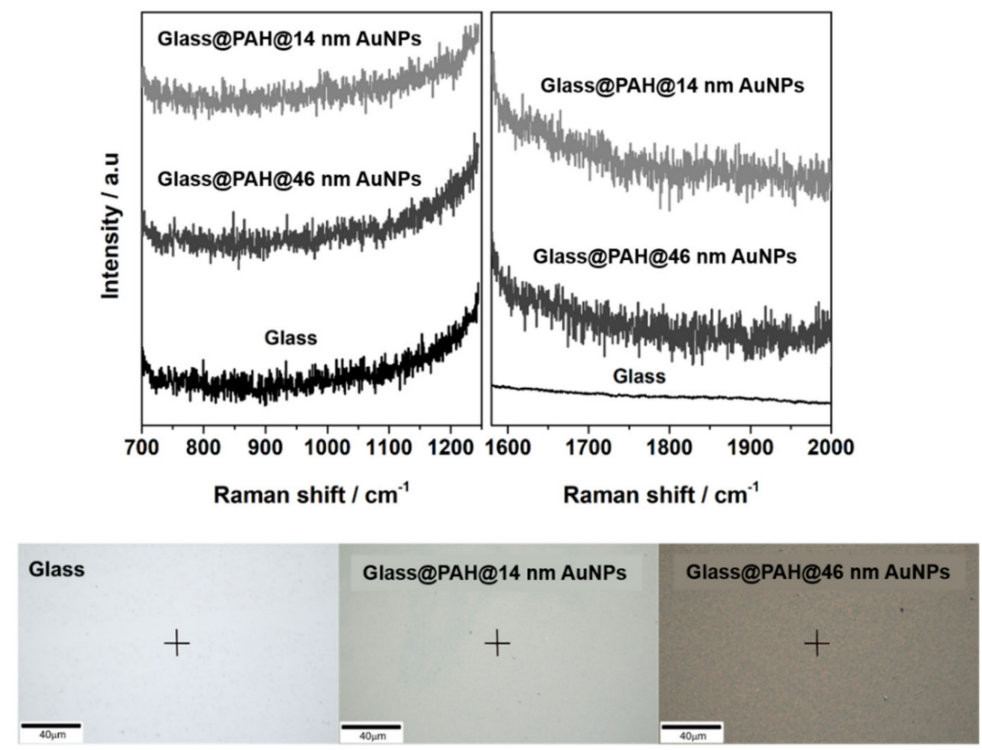

Figure A10. Representative Raman spectra for the substrates and glass slides without the presence of plastic particle samples. The spectra are split into the Raman shift range relevant for PS particles (left) and PET particles (right). The spectra are shown above images of the ROIs that the spectrum were obtained from, and the images are labelled with the relevant sample title. Laser power, scan speeds, and number of averaged accumulations for the samples can be viewed in Table A1. Scale for all is $40 \mu \mathrm{m}$.

\section{References}

1. Gündoğdu, S. Contamination of table salts from Turkey with microplastics. Food Addit. Contam. Part A 2018, 35, 1006-1014. [CrossRef] [PubMed]

2. Van Cauwenberghe, L.; Janssen, C.R. Microplastics in bivalves cultured for human consumption. Environ. Pollut. 2014, 193, 65-70. [CrossRef] [PubMed] 
3. Wagner, J.; Wang, Z.-M.; Ghosal, S.; Rochman, C.; Gassel, M.; Wall, S. Novel method for the extraction and identification of microplastics in ocean trawl and fish gut matrices. Anal. Methods 2017, 9, 1479-1490. [CrossRef]

4. Sobhani, Z.; Al Amin, M.; Naidu, R.; Megharaj, M.; Fang, C. Identification and visualisation of microplastics by Raman mapping. Anal. Chim. Acta 2019, 1077, 191-199. [CrossRef] [PubMed]

5. Allen, S.; Allen, D.; Phoenix, V.R.; Le Roux, G.; Durántez Jiménez, P.; Simonneau, A.; Binet, S.; Galop, D. Atmospheric transport and deposition of microplastics in a remote mountain catchment. Nat. Geosci. 2019, 12, 339-344. [CrossRef]

6. Lenz, R.; Enders, K.; Nielsen, T.G. Microplastic exposure studies should be environmentally realistic. Proc. Natl. Acad. Sci. USA 2016, 113, E4121-E4122. [CrossRef]

7. Ter Halle, A.; Jeanneau, L.; Martignac, M.; Jardé, E.; Pedrono, B.; Brach, L.; Gigault, J. Nanoplastic in the North Atlantic Subtropical Gyre. Environ. Sci. Technol. 2017, 51, 13689-13697. [CrossRef] [PubMed]

8. Käppler, A.; Fischer, D.; Oberbeckmann, S.; Schernewski, G.; Labrenz, M.; Eichhorn, K.-J.; Voit, B. Analysis of environmental microplastics by vibrational microspectroscopy: FTIR, Raman or both? Anal. Bioanal. Chem. 2016, 408, 8377-8391. [CrossRef] [PubMed]

9. Renner, G.; Schmidt, T.C.; Schram, J. Analytical methodologies for monitoring micro(nano)plastics: Which are fit for purpose? Curr. Opin. Environ. Sci. Health 2018, 1, 55-61. [CrossRef]

10. Gardiner, D.J. Introduction to Raman Scattering. In Practical Raman Spectroscopy; Gardiner, D.J., Graves, P.R., Eds.; Springer: Berlin/Heidelberg, Germany, 1989; pp. 1-12.

11. Jones, R.R.; Hooper, D.C.; Zhang, L.; Wolverson, D.; Valev, V.K. Raman Techniques: Fundamentals and Frontiers. Nanoscale Res. Lett. 2019, 14, 231. [CrossRef]

12. Rayleigh, L. On the Theory of Optical Images, with special reference to the Microscope. J. R. Microsc. Soc. 1903, 23, 474-482. [CrossRef]

13. Nie, S.; Emory, S.R. Probing Single Molecules and Single Nanoparticles by Surface-Enhanced Raman Scattering. Science 1997, 275, 1102-1106. [CrossRef] [PubMed]

14. Rodríguez-Lorenzo, L.; Álvarez-Puebla, R.A.; de Abajo, F.J.G.; Liz-Marzán, L.M. Surface Enhanced Raman Scattering Using Star-Shaped Gold Colloidal Nanoparticles. J. Phys. Chem. C 2010, 114, 7336-7340. [CrossRef]

15. Chalabi, H.; Schoen, D.; Brongersma, M.L. Hot-Electron Photodetection with a Plasmonic Nanostripe Antenna. Nano Lett. 2014, 14, 1374-1380. [CrossRef]

16. Xu, G.; Cheng, H.; Jones, R.; Feng, Y.; Gong, K.; Li, K.; Fang, X.; Tahir, M.A.; Valev, V.K.; Zhang, L. Surface-Enhanced Raman Spectroscopy Facilitates the Detection of Microplastics $<1 \mu \mathrm{m}$ in the Environment. Environ. Sci. Technol. 2020, 54, 15594-15603. [CrossRef]

17. European Commission. Commission recommendation of 18 October 2011 on the definition of nanomaterial. Off. J. Eur. Union 2011, 275, 38.

18. Lv, L.; He, L.; Jiang, S.; Chen, J.; Zhou, C.; Qu, J.; Lu, Y.; Hong, P.; Sun, S.; Li, C. In situ surface-enhanced Raman spectroscopy for detecting microplastics and nanoplastics in aquatic environments. Sci. Total Environ. 2020, 728, 138449. [CrossRef]

19. Langer, J.; Jimenez de Aberasturi, D.; Aizpurua, J.; Alvarez-Puebla, R.A.; Auguié, B.; Baumberg, J.J.; Bazan, G.C.; Bell, S.E.J.; Boisen, A.; Brolo, A.G.; et al. Present and Future of Surface-Enhanced Raman Scattering. ACS Nano 2020, 14, 28-117. [CrossRef]

20. Kneipp, K.; Kneipp, H.; Itzkan, I.; Dasari, R.R.; Feld, M.S. Ultrasensitive chemical analysis by Raman spectroscopy. Chem. Rev. 1999, 99, 2957-2976. [CrossRef]

21. Steinmetz, L.; Geers, C.; Balog, S.; Bonmarin, M.; Rodriguez-Lorenzo, L.; Taladriz-Blanco, P.; Rothen-Rutishauser, B.; Petri-Fink, A. A comparative study of silver nanoparticle dissolution under physiological conditions. Nanoscale Adv. 2020, 2, 5760-5768. [CrossRef]

22. Caldwell, J.; Lehner, R.; Balog, S.; Rhême, C.; Gao, X.; Septiadi, D.; Weder, C.; Fink, A.S.; Rothen-Rutishauser, B. Fluorescent Plastic Nanoparticles to Track their Interaction and Fate in Physiological Environments. Environ. Sci. Nano 2021, 8, 502-513. [CrossRef]

23. Enustun, B.; Turkevich, J. Coagulation of colloidal gold. J. Am. Chem. Soc. 1963, 85, 3317-3328. [CrossRef]

24. Brown, K.R.; Natan, M.J. Hydroxylamine Seeding of Colloidal Au Nanoparticles in Solution and on Surfaces. Langmuir 1998, 14, 726-728. [CrossRef]

25. Schindelin, J.; Arganda-Carreras, I.; Frise, E.; Kaynig, V.; Longair, M.; Pietzsch, T.; Preibisch, S.; Rueden, C.; Saalfeld, S.; Schmid, B.; et al. Fiji: An open-source platform for biological-image analysis. Nat. Methods 2012, 9, 676-682. [CrossRef]

26. Bubniene, U.; Ó́wieja, M.; Bugelyte, B.; Adamczyk, Z.; Nattich-Rak, M.; Voronovic, J.; Ramanaviciene, A.; Ramanavicius, A. Deposition of gold nanoparticles on mica modified by poly(allylamine hydrochloride) monolayers. Colloids Surf. A Physicochem. Eng. Asp. 2014, 441, 204-210. [CrossRef]

27. Liu, Z.; Yan, Z.; Bai, L. Layer-by-layer assembly of polyelectrolyte and gold nanoparticle for highly reproducible and stable SERS substrate. Appl. Surf. Sci. 2016, 360, 437-441. [CrossRef]

28. Vial, S.; Pastoriza-Santos, I.; Pérez-Juste, J.; Liz-Marzán, L.M. Plasmon Coupling in Layer-by-Layer Assembled Gold Nanorod Films. Langmuir 2007, 23, 4606-4611. [CrossRef]

29. Deegan, R.D.; Bakajin, O.; Dupont, T.F.; Huber, G.; Nagel, S.R.; Witten, T.A. Capillary flow as the cause of ring stains from dried liquid drops. Nature 1997, 389, 827-829. [CrossRef]

30. Yang, J.; Kim, H.; Lee, C.; Kim, S.; Wang, J.; Yoon, S.; Park, J.; Kim, J. Phase-field modeling and computer simulation of the coffee-ring effect. Theor. Comput. Fluid Dyn. 2020, 34, 679-692. [CrossRef] 
31. Lohani, D.; Basavaraj, M.G.; Satapathy, D.K.; Sarkar, S. Coupled effect of concentration, particle size and substrate morphology on the formation of coffee rings. Colloids Surf. A Physicochem. Eng. Asp. 2020, 589, 124387. [CrossRef]

32. Le Ru, E.C.; Etchegoin, P.G. Quantifying SERS enhancements. MRS Bull. 2013, 38, 631-640. [CrossRef]

33. Joseph, V.; Matschulat, A.; Polte, J.; Rolf, S.; Emmerling, F.; Kneipp, J. SERS enhancement of gold nanospheres of defined size. J. Raman Spectrosc. 2011, 42, 1736-1742. [CrossRef]

34. Link, S.; El-Sayed, M.A. Size and Temperature Dependence of the Plasmon Absorption of Colloidal Gold Nanoparticles. J. Phys. Chem. B 1999, 103, 4212-4217. [CrossRef]

35. Zhu, Z.; Zhu, T.; Liu, Z. Raman scattering enhancement contributed from individual gold nanoparticles and interparticle coupling Nanotechnology 2004, 15, 357-364. [CrossRef]

36. Israelsen, N.D.; Hanson, C.; Vargis, E. Nanoparticle Properties and Synthesis Effects on Surface-Enhanced Raman Scattering Enhancement Factor: An Introduction. Sci. World J. 2015, 2015, 124582. [CrossRef]

37. Besseling, E.; Wang, B.; Lürling, M.; Koelmans, A.A. Nanoplastic Affects Growth of S. obliquus and Reproduction of D. magna. Environ. Sci. Technol. 2014, 48, 12336-12343. [CrossRef]

38. Lê, Q.T.; Ly, N.H.; Kim, M.-K.; Lim, S.H.; Son, S.J.; Zoh, K.-D.; Joo, S.-W. Nanostructured Raman substrates for the sensitive detection of submicrometer-sized plastic pollutants in water. J. Hazard. Mater. 2021, 402, 123499. [CrossRef]

39. Rebollar, E.; Pérez, S.; Hernández, M.; Domingo, C.; Martín, M.; Ezquerra, T.A.; García-Ruiz, J.P.; Castillejo, M. Physicochemical modifications accompanying UV laser induced surface structures on poly(ethylene terephthalate) and their effect on adhesion of mesenchymal cells. Phys. Chem. Chem. Phys. 2014, 16, 17551-17559. [CrossRef]

40. Allen, V.; Kalivas, J.H.; Rodriguez, R.G. Post-Consumer Plastic Identification Using Raman Spectroscopy. Appl. Spectrosc. 1999, 53, 672-681. [CrossRef] 